$5-25-2021$

\title{
Translating evidence into impact: Advancing global girls' education
}

Population Council

Follow this and additional works at: https://knowledgecommons.popcouncil.org/

series_newsletters_researchimpact

How does access to this work benefit you? Let us know!

\section{Recommended Citation}

"Translating evidence into impact: Advancing global girls' education," Research Utilization and Impact Brief. Washington, DC: Population Council, 2021. 


\section{INFORMING PROGRAMS}

In India, Ethiopia, and Kenya, Council-generated education evidence has informed programming and influenced investment decisions, providing opportunities for girl-level change.

In India, the UDAYA study has generated staterepresentative data on the status of adolescents in Bihar and Uttar Pradesh, home to a quarter of the country's young people. Informed by years of Council research on transitions to adulthood, UDAYA is the largest longitudinal survey of its kind, providing evidence on multiple facets of adolescents' lives, including an array of educational and economic outcomes. By generating novel data around health and educational assets in these two states, UDAYA has provided important baseline indicators that are already being used to better understand the reach of state and national-level programs to support primary and secondary education, as well as adolescent well-being. UDAYA has also partnered with civil society organizations (CSOs) in Bihar and Uttar Pradesh to foster data use in advocacy efforts around girls' education. Through collaborative relationships with the Government of India and CSOs, UDAYA's publicly available datasets and analyses are well positioned to inform existing and future adolescent education interventions.

In Ethiopia, Biruh Tesfa ("Bright Future") has emerged as one of only a few rigorously evaluated programs in sub-Saharan African to support girls living in forced domestic servitude, girls who are trafficked, and girls living with disabilities. Utilizing adult female mentors to provide non-formal education and link girls to health services, the intervention significantly improved literacy and numeracy and increased girls' reports of social support and use of health services. Biruh Tesfa has reached over 75,000 out-of-school girls in urban areas across the country, and with additional

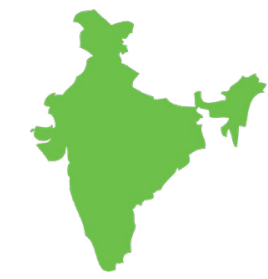

In India, UDAYA's novel and publicly available datasets are informing government education programs and supporting local advocacy efforts.

In Ethiopia, 'Biruh Tesfa for All' is expanding evidencebased safe spaces programming for girls living with disabilities or in domestic servitude.

In Kenya, the success of AGI-K's package of health and education interventions has generated government interest in scaling this initiative in Wajir County.

funding, "Biruh Tesfa for All" has scaled the intervention to reach an additional 10,500 girls in the cities of Addis Ababa, Adama, Bahir Dar, and Shashamene. The program continues to create inclusive public meeting spaces and learning materials for girls living with disabilities, and at the end of participation girls receive support to enroll in formal education and enter safer forms of work.

\section{In Kenya's Nairobi and Wajir counties, the} Adolescent Girl Initiative-Kenya (AGI-K) evaluated packages of multi-sectoral interventions, including a cash transfer to households conditioned on girls' school enrollment and attendance, to identify effective approaches for supporting marginalized 
girls' healthy transitions to adulthood. The randomized controlled trial comprising girl-, household-, and community-level interventions found overall positive effects on health, wealth, and girls' education, including primary school completion and schooling self-efficacy (e.g., selfconfidence to perform school-related tasks). Cost-effectiveness calculations demonstrated that delivering interventions as packages was better value for money than delivering them individually, and two-year follow-up results largely confirmed that targeted, timely investments in adolescent girls supported longer-term impacts on delayed childbearing. Acknowledging these successes, there is demonstrated interest from the senior level of government in Wajir County in scaling up AGI-K interventions through local delivery channels.

\section{LOOKING FORWARD}

At the global level, the Council's GIRL Center has emerged as a coordinating hub for generation, synthesis, and dissemination of research to support evidence-based programs and policies for girls' education. The Council continues to provide critical guidance on measuring gender equality in education and evaluating education-related interventions for girls. The GIRL Center's Evidence for Gender and Education Resource (EGER) is the first-ever free, searchable database for practitioners, researchers, donors, and decisionmakers to drive better education results around the world. EGER has mapped hundreds of programs and reviewed the evidence on what approaches improve girls' education outcomes, identifying where research gaps exist.

Informed by this work, EGER recently launched its 2021 Girls' Education Roadmap, a detailed plan to support alignment of demonstrated needs, evidence, and practice. New programs and evidence are constantly being added to the EGER database, and as the number of users who work on and invest in education policy, programming, and agenda-setting grows, it will increasingly be possible to trace its use.

The Council and its partners also rapidly responded to evolving data needs in the wake of the COVID-19 pandemic. Across multiple countries real-time evidence already indicates severe education disruptions for adolescent girls as well as boys, and Council researchers are pursuing global analyses to understand longer-term impacts (see text box for additional information).

\section{EDUCATION \& COVID-19}

Country-Specific Surveys: Between March and October 2020, the Council conducted a combined nine rounds of rapid phone-based surveys with more than 5,000 adolescents across Bangladesh, India, Kenya, and Mexico to understand the effects of COVID-19 on their lives. Across all four countries, adolescents, particularly girls, reported challenges to learning at home due to competing responsibilities such as household chores and lack of access to learning materials, digital technologies, or the internet.

Global Analyses: The Council is conducting a UNESCO-funded study to understand how COVID-19related school closures have affected outcomes in education, health, nutrition, and well-being among children and adolescents. The study will leverage EGER to understand how programs are addressing the gendered effects of school closures. 


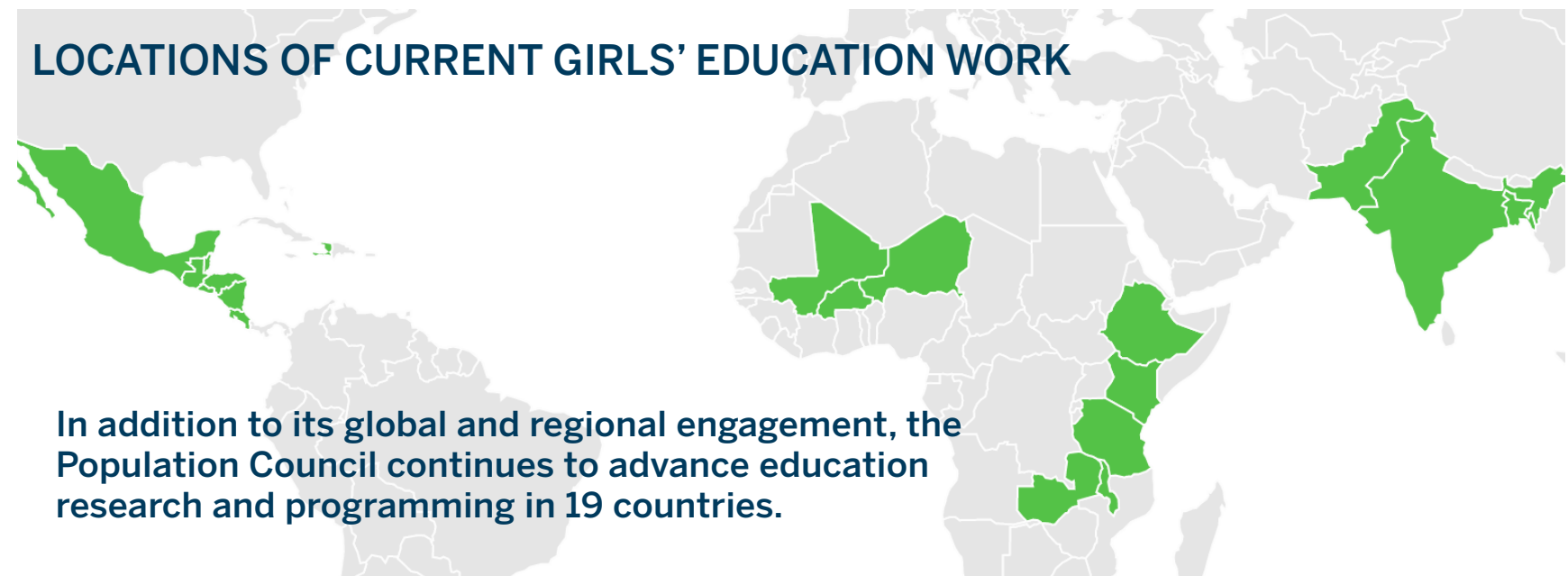

For more information:
$-1$
Visit the Girls' Education
Portfolio
Explore the EGER
Database
Learn About the Council's
Country-Level Work
Read the Girls' Education
Roadmap

\section{SELECTED RESOURCES}

\begin{tabular}{|c|c|}
\hline $\begin{array}{l}\text { Expansion } \\
\text { of the } \\
\text { Evidence } \\
\text { Base for } \\
\text { Girls' } \\
\text { Education }\end{array}$ & $\begin{array}{l}\text { - Girls' Education at the Population Council: Building Evidence to Accelerate } \\
\text { - Progress } \\
\text { - Measuring Gender Equality in Education: Lessons from } 43 \text { Countries } \\
\text { Delivering Results in Girls' Education: How to Evaluate What Works, What } \\
\text { Doesn't, and What We Don't Know }\end{array}$ \\
\hline $\begin{array}{l}\text { Country- } \\
\text { Level Girls' } \\
\text { Education } \\
\text { Impacts }\end{array}$ & $\begin{array}{l}\text { - Adolescent Girls Initiative-Kenya: Endline Evaluation Report } \\
\text { - UDAYA: Education, Employability, and Economic Inclusion } \\
\text { - Biruh Tesfa: Evaluation of a Safe Spaces Program for Girls in Ethiopia }\end{array}$ \\
\hline $\begin{array}{l}\text { COVID-19 } \\
\text { and Girls' } \\
\text { Education }\end{array}$ & $\begin{array}{l}\text { - Remember the fundamentals as we build back better in girls' education } \\
\text { - Adolescent Knowledge, Attitudes, and Practices Surveys from Bangladesh, } \\
\text { India, Kenya, and Mexico }\end{array}$ \\
\hline
\end{tabular}

The Population Council collaborates with program implementers, policymakers, researchers, and funding partners to advance evidence-based solutions to critical health and development challenges. Its research utilization and impact briefs feature recent highlights of our ongoing work to ensure evidence is translated into meaningful actions to improve lives from community to national, regional, and global levels.

Recommended citation: “Translating Evidence into Impact: Advancing Global Girls' Education.” Research Utilization and Impact Brief. Washington, D.C.: Population Council, 2021.

Cover Photo: (C) UNICEF Ethiopia 